www.jmscr.igmpublication.org

Impact Factor (SJIF): 6.379

Index Copernicus Value: 71.58

ISSN (e)-2347-176x ISSN (p) 2455-0450

crossrefDOI: https://dx.doi.org/10.18535/jmscr/v6i8.04

\author{
Journal Of Medical Science And Clinical Research

\title{
A Retrospective Study of Intussusception in Children
}

\author{
Authors \\ Pratik S. Shaparia ${ }^{1}$, Tarun D. Rochalni ${ }^{2}$, Asit L. Pathak ${ }^{3}$
}

\begin{abstract}
Background: Intussusception is invagination of one segment of intestine into other one. The proximal part known as Intussusceptum and distal part is called as Intussuscepiens. It is one of the common cause of paediatric intestinal obstruction, incidence of which may vary according to age and is common during infancy and early childhood. The male to female ratio is 3:1. The clinical presentation and aetiology may vary from patient to patients. Diagnosis is based on clinical ground and imaging methods like $X$ rays, Ultrasonography and CT scans. Treatment may be conservative or the surgical which depends on aetiology and pathology of the disease.

Aim: The study aims to find out age and sex difference, clinical symptoms and signs, seasonal variation, and various management aspects of intussusception in paediatric patients.

Materials and Methods: This was a retrospective study on paediatric patients. Patients aged below 12 years and diagnosed having intussusception by clinical or radiological ground were included in the study and patients who were above 12 years of age and having diagnosis other than intussusception were excluded. Summary: Intussusception is one of the common cause of intestinal obstruction in pediatric patients. Aetiology and presentation of intussusception may be variable. Most common age of presentation is $<1$ year and male child were more affected [1.5:1]. Abdominal pain was commonest symptom 100\%] and tenderness of abdomen was most common elicited sign [88\%]. X ray abdomen and Ultrasonography was commonly used imaging technique [100\%]. Most of the patients were managed conservatively [72\%]. Resection and anastomosis of intestine was commonly performed procedure in those who underwent surgical intervention [57\%]. Seasonal variation was observed in the study, more number of incidence were happened in the season of monsoon [56\%].
\end{abstract}

Keywords: Intussusception, Acute intestinal obstruction, Lead points.

\section{Introduction}

The term "intussusception" is defined when one portion of the gut becomes invaginated with another immediately adjacent to $\mathrm{it}^{[1]}$. The peak age of presentation is 4 to 8 months when weaning is started $^{[2]}$. In infancy and early childhood usual reason is lymphoid hyperplasia, but in grown up children and adults the cause is some lead point pathogenic conditions like Polyps, Lipoma, Malignancies, Meckel's diverticulum etc ${ }^{[3]}$. Overall, the male-to-female ratio is approximately $3: 1$. With advancing age, gender difference becomes marked; in patients older than 4 years, the male-to-female ratio is $8: 1^{[2,4]}$.

Most common type of intussusception is Ileocolic $77 \%$ followed by Ileo-ileo-colic - 12\%, Ileoileal $4 \%$, Colocolic $-2 \%$, Multiple $-1 \%$, Retrograde $0.2 \%$.

In approximately $2-12 \%$ of children with intussusception, a surgical lead point is found. Occurrence of surgical lead points increases with 
age and indicates that the probability of nonoperative reduction is highly unlikely. The lead point can be a Meckel's diverticulum, enlarged mesenteric lymph node, benign or malignant tumors of the mesentery or of the intestine, including lymphoma, polyps, ganglioneuroma and hamartomas associated with Peutz-Jeghers syndrome, mesenteric or duplication cysts, sub mucosal hematomas, which can occur in patients with HSP and coagulation dyscrasias and others ${ }^{[5,6]}$. The symptoms include a classic triad of vomiting, abdominal pain, and passage of blood per rectum (red currant jelly stool) which occurs in only one third of patients. Pain in intussusception is colicky, severe, and intermittent. Initially, vomiting is nonbilious and reflexive, but when the intestinal obstruction occurs, vomiting becomes bilious. The hallmark physical findings in intussusception are a right hypochondrium sausage-shaped mass ${ }^{[7]}$ and emptiness in the right lower quadrant (Sign of Dance).

\section{Aims and Objectives}

To study the:

- Gender preponderance

- Age of presentation

- Seasonal variation

- Etiological factors

- Lead points

- Clinical features

- Investigations

- Non Operative and Operative measures of management

\section{Material and Method}

This was a retrospective descriptive study of 50 cases of intussusception conducted in Department of Surgery in a tertiary care hospital among patients aged below 12 years between May 2017 to May 2018. Retrospective analysis was done based on the medical records of the patients. The database includes demographic data, clinical presentation and their duration, hospital admission dates, diagnostic and treatment procedures, and status at the time of discharge or death in hospital.

\section{Inclusion Criteria}

The verified diagnosis of intussusceptions in patients by imaging (ultrasound, enema, and/or computed tomography (CT) or surgical exploration.

\section{Exclusion Criteria}

Patients were excluded if the diagnosis of intussusceptions was not validated or patients who were above 12 years of age.

\section{Observation and Analysis}

Table 1 Age distribution in cases of intussusception

\begin{tabular}{|l|c|c|}
\hline Age In Years & Total Numbers & Percentage \\
\hline $0 \mathrm{TO}<1 \mathrm{YR}$ & 22 & $44 \%$ \\
\hline $1 \mathrm{TO}<2 \mathrm{YR}$ & 10 & $20 \%$ \\
\hline $2 \mathrm{TO}<5 \mathrm{YR}$ & 14 & $28 \%$ \\
\hline $5 \mathrm{TO}<12 \mathrm{YR}$ & 4 & $08 \%$ \\
\hline
\end{tabular}

Table 2: Sex distribution

\begin{tabular}{|l||c|c||}
\hline Sex & Total Numbers & Percentage \\
\hline Male & 30 & $60 \%$ \\
\hline Female & 20 & $40 \%$ \\
\hline
\end{tabular}

Table 3: Clinical symptoms

\begin{tabular}{|l|c|c|}
\hline Symptoms & Total No & Percentage \\
\hline Abdominal pain & 50 & $100 \%$ \\
\hline Abdominal distention & 22 & $44 \%$ \\
\hline Fever & 18 & $36 \%$ \\
\hline Nausea / Vomiting & 46 & $92 \%$ \\
\hline Constipation & 12 & $24 \%$ \\
\hline Loose stool & 14 & $28 \%$ \\
\hline
\end{tabular}

Figure 1: Clinical signs of intussusceptions

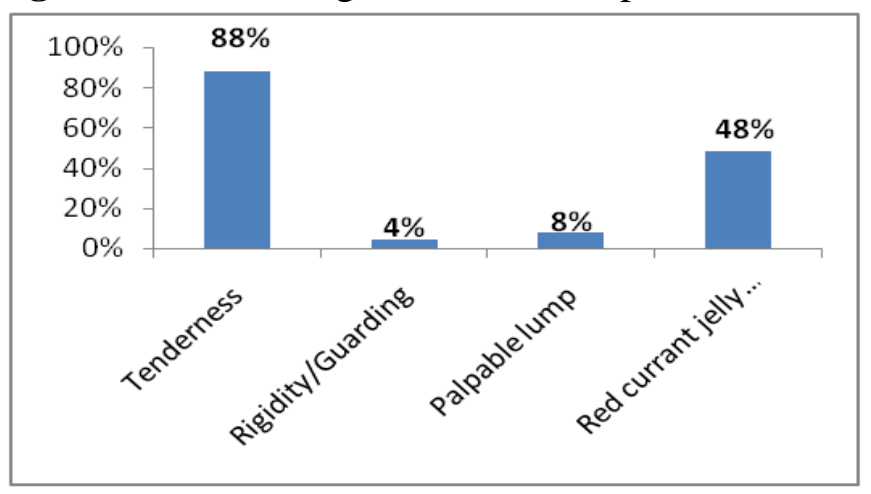

Table 4: X-ray abdomen findings

\begin{tabular}{|l|c|c|}
\hline X Ray Reporting & Total No & Percentage \\
\hline Gas Filled Bowel Loops & 46 & $92 \%$ \\
\hline Typical step-ladder pattern & 04 & $08 \%$ \\
\hline $\begin{array}{l}\text { Free gas under both domes } \\
\text { Of diaphragm }\end{array}$ & 00 & $00 \%$ \\
\hline Total & $\mathbf{5 0}$ & $\mathbf{1 0 0} \%$ \\
\hline
\end{tabular}


Figure 2: Types of intussusceptions observed

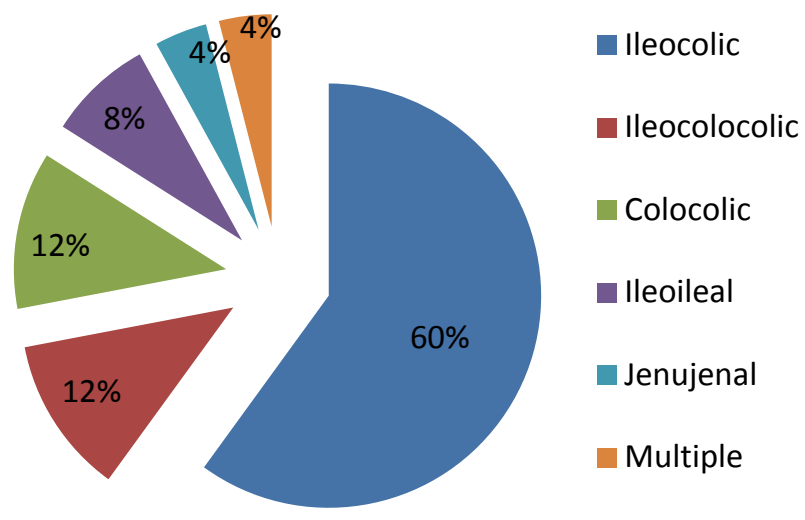

Table 5: Seasonal incidence of intussusception

\begin{tabular}{|l|c|c|}
\hline Season & No. of cases & Percentage \\
\hline $\begin{array}{l}\text { Summer } \\
\left(3^{\text {rd }}-6^{\text {th }} \text { month }\right)\end{array}$ & 08 & $16 \%$ \\
\hline $\begin{array}{l}\text { Monsoon } \\
\left(7^{\text {th }}-10^{\text {th }} \text { month }\right)\end{array}$ & 28 & $56 \%$ \\
\hline $\begin{array}{l}\text { Winter } \\
\left(11^{\text {th }}-2^{\text {nd }} \text { month }\right)\end{array}$ & 14 & $28 \%$ \\
\hline Total & $\mathbf{5 0}$ & $\mathbf{1 0 0 \%}$ \\
\hline
\end{tabular}

Table 6: Per operative findings of Intussusception

\begin{tabular}{|l|c|c|}
\hline Types & $\begin{array}{c}\text { No. Of operated } \\
\text { cases }\end{array}$ & $\begin{array}{c}\text { Percent } \\
\text { age }\end{array}$ \\
\hline Ileocolic & $\mathbf{0 7}$ & $\mathbf{5 0 \%}$ \\
\hline Ileocolocolic & $\mathbf{0 2}$ & $\mathbf{1 4 \%}$ \\
\hline Colocolic & $\mathbf{0 1}$ & $\mathbf{0 7 \%}$ \\
\hline Ileoileal & $\mathbf{0 2}$ & $\mathbf{1 4 \%}$ \\
\hline Jejunojejunal & $\mathbf{0 1}$ & $\mathbf{0 7 \%}$ \\
\hline Multiple & $\mathbf{0 1}$ & $\mathbf{0 7 \%}$ \\
\hline
\end{tabular}

Figure 3: Management of intussusception

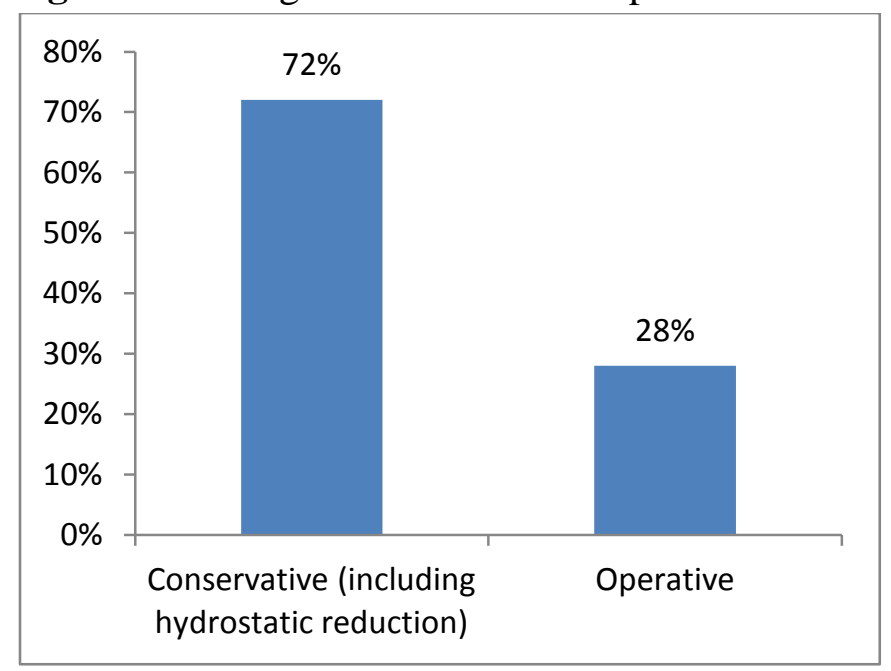

Table 7: Surgical procedure performed

\begin{tabular}{|c|c|c|}
\hline Surgical procedure & No. of cases & Percentage \\
\hline $\begin{array}{lr}\text { Reduction } & \text { of } \\
\text { intussusception } & \text { with } \\
\text { caecopexy } & \\
\end{array}$ & 02 & $14 \%$ \\
\hline $\begin{array}{lr}\text { Reduction } & \text { of } \\
\text { intussusception } & \text { with } \\
\text { caecopexy } & \text { and } \\
\text { appendicectomy } & \end{array}$ & 04 & $28 \%$ \\
\hline $\begin{array}{l}\text { Intestinal resection } \\
\text { and anastomosis }\end{array}$ & 08 & $57 \%$ \\
\hline
\end{tabular}

\section{Discussion}

Here we have studied the 50 cases of paediatric intussusceptions in the period of May 2017 to May 2018.

\section{-Age Incidence}

The study included the age group ranging from 0 to 12 years, the most no. of cases were from 0 to 1 year (44\%). Then the incidence decreases as the age increases. In a study done by NK Hazra, OB Karki, M Verma, D Rijal et al., included 26 paediatric patients with maximum patients were of age $<1$ year $^{[1]}$.

\section{-Sex Incidence}

Most patients in this study were male (60\%). Male patients were one and half times more than the female patients. In the study done by NK Hazra, OB Karki, et al., the male to female patients ratio was $1.6: 1^{[1]}$.

\section{-Clinical Symptoms}

The most common presenting symptom was abdominal pain present in all the cases (100\%). After pain, next most common symptom was nausea / vomiting present in almost $72 \%$ patients. Fever and abdominal distention were also the common symptoms present in $36 \%$ and $44 \%$ patients respectively. In study done by $\mathrm{N}$ K Hazra, O B Karki et. al., abdominal pain was the most common presenting symptom present in $73 \%$ patients. Vomiting was present in almost $42 \%$ patients. Abdominal distention was present in $19 \%$ patients $^{[1]}$. In a study done by P L Chalya, N M Kayange, A B Chandika abdominal pain was present in only $14.3 \%{ }^{[8]}$. Abdominal distention and fever were present in $85.7 \%$ and $14.3 \%$ patients respectively. 


\section{-Clinical Signs}

Tenderness was the most common sign present among the patients in the study. Tenderness over para-umbilical region were present in almost $88 \%$ patients. The second most common sign was the red current Jelly stool (48\%). Other significant signs were palpable lump and rigidity /guarding which were present in $08 \%$ and $04 \%$ patients. In the study conducted by P L Chalya, N M Kayange, A B Chandica tenderness was present in $76 \%$ patients. Red current Jelly stool was present in $53 \%$ patients. However, palpable lump and rigidity/guarding were present only in $10 \%$ and $08 \%$ patients ${ }^{[8]}$.

\section{-Per Rectal Examination}

All the patients in the study underwent per rectal examination, out of them $48 \%$ showed blood stained stool or blood stained examining finger. In study done by N K Hazra, OB Karki et. al., 38\% patients showed bleeding per rectum. In study done by Chalya and Kayange et. al., 10.7\% showed bleeding per stool ${ }^{[8]}$.

\section{-Types of Intussusception}

Most frequent type was ileo colic present in almost $60 \%$ of patients. This was followed by Ileocolo colic and colo colic intussusception present in $12 \%$ patients each. In study conducted by Chalya and Kaynge et. al., Ileo colic intussusception was common, present in almost $67.9 \%$ patients, followed by colo colic present in $25 \%$ patients ${ }^{[8]}$. In study conducted by Hazra and Karki et. al., 76\% patients showed ileo colic intussusception followed by ileoileal type present in $12 \%$ patients $^{[1]}$.

\section{-Seasonal Variation}

The study showed the seasonal variation in the incidence of intussusception. Most no. of cases were reported in the season of Monsoon(56\%) followed by winter $(28 \%)$.

\section{-Management of Intussusception}

Out of 50 patients studied in the study, most of them were managed conservatively with USG guided hydrostatic reduction (72\%) and only $28 \%$ patients required surgical intervention. In the study conducted by Hazra, Karki and Verma et al., all the patients had to undergone surgical intervention for the management ${ }^{[1]}$.
-Operative Procedure In The Management of Intussusception

Of the operated patients, $57 \%$ underwent resection and anastomosis, $28 \%$ were treated by reduction of intussusception followed by caecopexy and appendicectomy and $14 \%$ were managed by reduction of intussuception and caecopexy. A study conducted by N K Hazra, OB Karki, M Verma, D Rijal, Abhijit De and B Nath shows that 69\% patients was treated by Reduction of intussusception and appendectomy with Ileocaecopexy and 08\% patients were treated with resection and anastomosis $^{[1]}$.

\section{Conclusion}

Intussusception is one of the common cause of intestinal obstruction in pediatric patients. The common age of presentation is in infancy with incidences in male were common than female. Abdominal pain was the commonest symptom and tenderness was commonest sign. Most patients were treated conservatively.

\section{Acknowledgement}

We are thankful to Dr. S.G.Mehta (M.S, Professor), Dr. D.P. Vasavada (M.S, Professor), Dr. N.K. Goswami (M.S, Associate Professor) for their inputs on the subject and to the nursing staff of our unit.

\section{References}

1. NK Hazra, OB Karki et.al: Intussusception in Children: a short term analysis in tertiary care hospital. American journal of public health research, 2015 Vol. 3, No.4A, 53-56.

2. Shapkina AN, Shapkin W, Nelubov IV, Pryanishena LT: Intussusception in children: 11-year experience in Vladivostok. Pediatr Surg Int 2006, 22:901-904.

3. Murphy TV, Gargiullo PM, Massoudi MS, Nelson DB, Jumaan AO, Okoro CA, et al. Intussusception among infants given an oral rotavirus vaccine. N Engl J Med. 2001; 344: 564-572.

4. Parashar UD, Holman RC, Cummings KC: Trends in intussusceptionassociated 
hospitalizations and deaths among US infants. Pediatrics 2000, 106:1413-1421.

5. Banapour P, Sydorak RM, Shaul D. Surgical approach to intussusception in older children: Influence of lead points. J Pediatr Surg. 2015 Apr. 50(4):647-50

6. Ein SH. Leading points in childhood intussusception. J Pediatr Surg. 1976 Apr. 11(2):209-11

7. Anthony L. Principles of paediatric surgery. In: Williams NS, O'connell PR, Mc Caskie AW,editor. Bailey \& Love's Short practice of surgery. $27^{\text {th }}$ edition. Florida:CRC Press taylor \& Francis group; 2018.129.

8. Chalya PL, Kayange NM, Chandika AB. Childhood intussusceptions at a tertiary care hospital in northwestern Tanzania: a diagnostic and therapeutic challenge in resource-limited setting. Italian Journal of Pediatrics 2014, 40:28. 